\title{
¿ Presidencialismo y gobernabilidad democrática en América Latina
}

\author{
Presidentialism and democratic \\ governance in Latin America
}

\author{
JULIO CÉSAR FERNÁNDEZ TORO \\ Profesor de la Escuela de Estudios \\ Políticos y Administrativos. Universidad \\ Central de Venezuela. \\ fernandeztoro@gmail.com \\ DOI: https://doi.org/10.7203/cc.1.19051 \\ Fecha de recepción: 19/10/2020 \\ Fecha de aceptación: 11/11/2020
}

\section{Resumen}

El artículo analiza el posible impacto del sistema de gobierno presidencial sobre la gobernabilidad democrática en América Latina, que ha sido el objeto del debate presidencialismo vs. parlamentarismo desarrollado en los ambientes políticos y académicos. El debate se examina mediante una visión integral de la relación entre la variable institucional y el resultado político. Con ese propósito, el análisis se apoya en la idea de separación de poderes, un principio apodíctico del constitucionalismo democrático, que persigue con el diseño de un arreglo orgánico-funcional limitar el poder de los gobernantes para preservar la libertad de los ciudadanos. Por último, el artículo enumera las debilidades y desafíos de las presidencias latinoamericanas, y las alternativas para mejorar su capacidad de gestión y para garantizar la gobernabilidad democrática.

Palabras clave

Separación de poderes; sistema de gobierno; presidencialismo; parlamentarismo; gobernabilidad democrática; constitucionalismo; América Latina.

\section{Abstract}

The article discusses the potential impact of the presidential governance system on democratic governance in Latin America, which has been the subject of the presidential vs. parliamentary debate, developed in political and academic settings. The debate is examined through a comprehensive view of the relationship between the institutional variable and the political outcome. To this end, the analysis is based on the idea of separation of powers, an apodictic principle of democratic constitutionalism, which he pursues with the design of an organic-functional arrangement limiting the power of rulers to preserve the freedom of citizens. Finally, the article lists the weaknesses and challenges of Latin American presidencies, and alternatives to improve their management capacity and to ensure democratic governance.

\section{Keywords}

Separation of powers; system of government; presidentialism; parliamentaryism, democratic governance; constitutionalism; Latin America. 
I. La idea de separación de poderes en los sistemas de gobierno. 1. La formulación de Montesquieu. 2. La separación de poderes en los sistemas de gobierno stricto sensu - II. EI debate: presidencialismo vs. parlamentarismo en América Latina. 1. ¿Qué se discute en el debate parlamentarismo vs. presidencialismo? 2. El asunto del poder en los sistemas de gobierno presidenciales. 3. Sobre la condición congénita de los sistemas de gobierno. - III. Un abordaje integral del presidencialismo en América Latina. 1. Problemas cuyo origen es el diseño institucional del sistema de gobierno presidencial. 2. Problemas cuyo origen se encuentra ubicado en la cultura social y en la praxis política. 3. Problemas cuyo origen se encuentra en la capacidad de gobierno. - IV. Adecuación de los sistemas de gobierno presidenciales para garantizar la gobernabilidad democrática en América Latina. 1. De naturaleza política. 2. De flexibilización organizacional para la adaptación a los cambios. Bibliografía.

I. La idea de separación de poderes en los sistemas de gobierno

1. La formulación de Montesquieu

A pesar de que algunos autores han llegado a afirmar que el concepto apodíctico de separación de poderes tiene sus orígenes en la Grecia Antigua, es indudable que como se lo comprende en la modernidad no se puede encontrar antes de su formulación por el Barón de La Brède y Montesquieu (1688-1755) en su obra El Espíritu de las Leyes y con las adaptaciones de los diseños constitucionales surgidos durante las revoluciones atlánticas.

Si bien desde la antigüedad los pensadores no se propusieron, ni podían, esbozar un concepto como el del Barón de La Brède, empero, en general, sí pretendieron regular y limitar el poder del gobernante. Trataron de resolver lo que podría denominarse la ruta hacia la tiranía, esto es, que si un gobernante acumula en sí todo el poder podría ejercerlo sin límites, si lo ejerce sin límites podría gobernar arbitrariamente, si es arbitrario podría violentar la libertad de los ciudadanos, y si violenta la libertad de los ciudadanos sería un gobierno tiránico. Por ello distintos pensadores a lo largo de la historia formularon maneras de cortar la ruta hacia la tiranía, como por ejemplo: 1) El sometimiento del gobernante a las leyes. La famosa máxima de que el buen gobierno era el de las leyes y no el de los hombres. 2) La elección de los gobernantes por votación -el sufragio-, o mediante selección por medio la suerte-el sorteo-. 3) Restringiendo el ejercicio del gobernante a un período de tiempo -opuesto al gobierno vitalicio y hereditario-. 4) Y mediante el control de los súbditos o 
de los ciudadanos sobre el gobierno, a través de una representación, ya fuera estamental o democrática, o por su participación directa.

El aporte de Montesquieu, desde su perspectiva monárquica, fue comprender que el sometimiento a la ley y la participación estamental en Europa eran mecanismos imprescindibles, aunque no suficientes, y partiendo de la raíz del problema consideró que había que evitar que el gobierno se concentrara en una sola mano o en un órgano colectivo. En palabras de Montesquieu (1748/2003: 119): "aquellos príncipes que han querido hacerse déspotas, siempre han empezado por acumular en su persona todas las magistraturas, y algunos reyes de Europa todos los grandes cargos de su Estado", bajo la premisa de que todo ser humano dotado de poder abusará de este "hasta dónde encuentre límites".

Pero, ¿cómo evitarlo? Pues Montesquieu encontró una solución en la física newtoniana: "Para que no se pueda abusar del poder es necesario que, por la disposición de las cosas, el poder refrene al poder" (1748/2003: 118). Esa formulación teórica, por la que un poder refrena a otro poder, es lo que sustenta un sistema de equilibrio entre poderes y de controles mutuos entre ellos -système d'équilibre et contrôles o cheks and balance system-. Propuesta que ejemplificó en el sistema de gobierno existente en la Inglaterra de su época, a la que calificó como una nación "cuya constitución' tiene por objeto directo la libertad política" (Arroyo, 2002: 118).

Ahora bien, al estudiar la constitución inglesa el Barón de La Brède dice que todo Estado posee "tres géneros de poder: el poder legislativo, el poder ejecutivo de lo que depende el derecho de gentes [en la actualidad el derecho internacional] y el poder ejecutivo de lo que depende el derecho civil [el derecho interno]" (1748/2003: 118). Y como se desprende de la lectura de EI Espíritu de las Leyes, en particular de su Libro XI Montesquieu también identifica y describe tres géneros de poder: legislativo, ejecutivo y de juzgar, agregando, que sin embargo el poder judicial es neutro o nulo. "De los tres poderes que hemos hablado, el de juzgar es, en cierto sentido, nulo. No quedan, entonces, más que dos" (1748/2003: 121): el poder legislativo y el poder ejecutivo. De allí que Montesquieu estableciera la representación de los nobles -la Cámara de los Lores- como un poder que controla o modera el ejercicio del poder legislativo popular -la Cámara de los Comunes- y del poder ejecutivo -la Corona-, y los dos últimos al primero.

Bajo la perspectiva anterior, en propiedad Montesquieu está interesado únicamente en lo que hoy se denomina como un sistema de gobierno stricto sensu $u^{2}$, esto es, exclusivamente en la conformación y relacionamiento de dos poderes a los que se le atribuye poseer una racionalidad fundamentalmente política, el legislativo y el ejecutivo. Para el Barón de La Brède (1748/2003: 124), al hablar de "la constitución fundamental del gobierno", se refiere a las dos partes que conforman el cuerpo legislativo, los representantes de los nobles y los representantes de los comunes, reunidos por separado, y al poder ejecutivo, a los que seguidamente los menciona como "Estos tres poderes". En clave de la actualidad, solo se refiere a dos poderes, el legislativo y el ejecutivo. Con

1 En este caso, y antes de la revolución angloamericana, la locución "constitución" se refería a la forma o manera como se estructuraba el gobierno, y no como la conocemos hoy referida a un texto normativo fundacional y fundamental de los Estados-nación.

2 Se utiliza la expresión "sistema de gobierno" como la categoría tradicional del derecho constitucional que se refiere, en latus sensu, a la conformación y relacionamiento entre todos los poderes del Estado que se constituyen bajo un criterio orgánico-funcional, y en stricto sensu, como la conformación y relacionamiento exclusivamente entre el poder legislativo y el poder ejecutivo. 
dicho aserto, es obvio que para Montesquieu la solución será la necesidad de dividir o distribuir el poder público o el poder del Estado en: el monarca que es titular del poder ejecutivo; los representantes de los nobles como una de las dos partes del poder legislativo, o uno de sus dos órganos, y con algunas funciones judiciales excepcionales; $y$, los representantes del pueblo con la otra parte del poder legislativo, o su otro órgano; excluyendo el poder de juzgar. "Compuesto el cuerpo legislativo de dos partes, la una refrenará a la otra por el recíproco derecho de veto. Ambas se hallarán a su vez refrenadas por el poder ejecutivo que, a la suya, lo estará por el legislativo" (1748/2003: 124), al tiempo que el autor establece el principio de colaboración entre poderes, al indicar que "Estos tres poderes (...) por el necesario movimiento de los acontecimientos, se hallan obligados a actuar, tendrán que hacerlo concertadamente".

La importancia de la formulación del Barón de La Brède es que, adaptada por el pensamiento revolucionario angloamericano a los principios de soberanía popular y de forma de gobierno democrática, se fue imponiendo poco apoco como un principio imprescindible del constitucionalismo en el hemisferio occidental, hasta constituir en la actualidad un valor apodíctico inherente a la doctrina democrática. Hoy no se concibe la democracia sin una efectiva separación de poderes.

Bajo tal concepción se sustenta el diseño de los actuales sistemas de gobierno en su acepción stricto sensu, que bajo un criterio orgánico-funcional sustenta una distribución de funciones de las potestades del Estado entre los órganos superiores o autoridades máximas legislativas y ejecutivas con la pretensión de ser una solución universal para impedir el despotismo. Mas, sin embargo, los desarrollos históricos constitucionales que estructuraron los sistemas de gobierno nacionales en la modernidad tomaron dos caminos paradigmáticos distintos: el parlamentarismo en Europa y el presidencialismo en América.

Ahora bien, bajo la idea política de separación de poderes, la interrogante que se ha mantenido por décadas en el debate académico y político latinoamericano, es con cuál de dichos sistemas, el presidencial o el parlamentario, se logra una mejor limitación del poder de los gobernantes para preservar la libertad.

\section{La separación de poderes en los sistemas de gobierno stricto sensu}

La formulación teórica de Montesquieu, mediante una repartición de las potestades del Estado contemporáneo entre sus distintos poderes, conlleva a que cada órgano supremo de los poderes legislativo y ejecutivo, desconcentrados bajo un criterio político funcional, goce de una autonomía otorgada constitucionalmente como centros de imputación normativa. Empero, la autonomía no es un atributo que le permita a los órganos superiores de los poderes ejercer sus competencias con absoluta discrecionalidad, por lo que el ejercicio de sus competencias respectivas estará limitado por la existencia de controles contemplados para las dos situaciones siguientes: 1) En el ejercicio lícito de competencias, los órganos superiores de los poderes las ejecutan con autonomía, aunque sometido dicho ejercicio a controles exclusivamente de oportunidad y de conveniencia. Si bien el órgano al ejercer su competencia no comete ningún ilícito, sin embargo, para que el acto o acción resultante sea válido requiere que otro órgano evalúe -controle- su conveniencia u oportunidad. En el caso de que la evaluación sea negativa, el acto o acción es impedido, extinguido, diferido o modificado. 2) En el ejercicio ilícito de competencias. En este caso, si bien los órganos superiores de los poderes ejecutan discrecionalmente competencias, empero, debido a la existencia de supuestos de hecho previstos expresamente por los ordenamientos jurídicos como inaceptables, tales como la usurpación 
de funciones, la desviación de poder o el abuso de poder, ese ejercicio ilícito será bloqueado por controles provenientes de otros órganos que subsanarán el vicio o el ejercicio irregular de competencias. De esta manera, mediante una distribución competencial de rango constitucional, se concreta la separación de poderes bajo un criterio orgánico-funcional que da lugar a las estructuras de los sistemas de gobierno. Así, el gobierno se estructura en un eje horizontal de distribución de funciones atribuidas a órganos estatales desconcentrados $y$, a la vez, coordinados, sometidos a un sistema de equilibrio de poderes que se controlan mutuamente.

En la acepción stricto sensu, los sistemas de gobierno únicamente abarcan a los poderes legislativo y ejecutivo, cuya naturaleza y función se consideran de racionalidad fundamentalmente política y, por tanto, excluyendo al poder judicial, al que se le atribuye una racionalidad más bien tecno-jurídica. Dependiendo de los diseños orgánico-funcionales que estructuran los sistemas de gobierno, y de las consecuentes relaciones bidireccionales de poder se da origen a los distintos tipos de sistema de gobierno, como lo serían los paradigmáticos presidencial y parlamentario, y sus intermedios, conocidos como mixtos, híbridos o de fases alternas.

Ahora bien, la referencia clásica de sistemas de gobierno stricto sensu, y toda tipología hasta hoy elaborada, se sustenta en la dicotomía entre los dos sistemas de gobierno paradigmáticos, el parlamentario y el presidencial, a la que se encuentra anclado el debate en América Latina. Lo que lamentablemente constituye una limitación de origen en el debate, reduciendo el margen de análisis de la relación entre los sistemas de gobierno y la gobernabilidad democrática y restringiendo la consideración de alternativas no contempladas por dicha dicotomía. La diferencia entre los sistemas de gobierno presidencial y parlamentario puede sintetizarse en los elementos siguientes.

a) En cuanto a las jefaturas de Estado y de gobierno.

En el sistema parlamentario existe una separación entre las funciones de jefatura de Estado, que están atribuidas a un rey si es un Estado monárquico -España- o a un presidente si se trata de uno republicano -Portugal-, y las funciones de jefatura de gobierno, que están asignadas a lo que genéricamente se llama primer ministro, como en Portugal, y que en España recibe el nombre de presidente del gobierno. En el presidencialismo, las funciones de jefatura de Estado y de gobierno recaen en el mismo cargo o autoridad: el presidente.

b) En cuanto al origen de la legitimidad del Parlamento y del Ejecutivo.

En el sistema parlamentario, el pueblo elige democráticamente a los integrantes del parlamento y el jefe de Estado le solicita normalmente al líder de la primera mayoría parlamentaria que forme gobierno; éste, para ser jefe de gobierno -primer ministro o presidente del gobierno-, requiere un voto de confianza del parlamento. El resultado es que el parlamento posee una legitimidad de origen directa por votación popular, mientras que el poder ejecutivo tiene una legitimación derivada de la del parlamento y, por lo tanto, indirecta. En cambio, en el sistema presidencial, tanto los parlamentarios como el presidente son electos por el voto popular, de allí que tanto el poder legislativo como el poder ejecutivo poseen legitimidad de origen directa y propia. 
En el sistema parlamentario, el primer ministro o jefe del gobierno y los ministros pueden y suelen ser también parlamentarios, sin perder esta condición -separación relativa de funciones-. Por el contrario, en el sistema presidencial, los ministros, el presidente y cualquiera que ocupe otro cargo ejecutivo no puede seguir siendo parlamentario -separación radical de funciones-.

d) En cuanto al control político del Parlamento sobre el Ejecutivo.

En el sistema parlamentario, el primer ministro o jefe del gobierno para asumir el cargo suele requerir de un voto de confianza del parlamento y puede ser destituido por la aprobación de un voto parlamentario de censura. Ambos procedimientos son rutinarios. En el sistema presidencial, el presidente no requiere de voto de confianza del parlamento y su destitución del cargo suele ser un complejo y extraordinario procedimiento de juicio político, que no depende exclusivamente del parlamento.

e) En cuanto al signo político de los poderes según el resultado electoral.

En el sistema parlamentario ambos poderes siempre estarán conducidos por el mismo partido o alianza de partidos. En el sistema presidencial, dado que el presidente y los parlamentarios son electos directamente por el voto popular, puede darse el caso de que la mayoría del parlamento sea de un partido, o alianza de partidos, distintos al sector político del presidente.

Bajo los anteriores criterios diferenciadores, de acuerdo a cómo se da la legitimación y conformación de los órganos legislativos y ejecutivos, y a cómo se relacionan entre sí, en el Derecho Constitucional se han formulado las distintas tipologías, de las que se han desprendido clases de sistema de gobierno -stricto sensu- bajo los calificativos de: presidenciales, parlamentarios, mixtos o híbridos, y de fases alternas. Tipos de sistemas de gobierno que en algunos casos pueden ser imprecisos al tratar de catalogar a los sistemas latinoamericanos.

En la especificidad de América Latina, el debate enfocado en la dicotomía: presidencialismo vs. parlamentarismo se originó a finales de la década de los 80 y se desarrolló con fuerza en los 90's del siglo pasado, perviviendo hasta nuestros días gracias a una cadena de hechos en la región que ha mantenido encendida la hoguera de la disputa, tales como: el golpe de Estado del 28 de junio de 2009 contra el Presidente Manuel Zelaya de Honduras, después del impasse con el parlamento sobre la convocatoria presidencial a un referendo para que una asamblea constituyente modificara el orden constitucional hondureño; en Bolivia, el desacato del Presidente Evo Morales al referendo popular del 21 de diciembre de 2016 que ratificó la imposibilidad constitucional de que se presentara nuevamente como candidato a la presidencia para un nuevo mandato; el proceso de continua acumulación inconstitucional de poder fáctico del Presidente Nicolás Maduro en Venezuela, que se desencadenó a partir de que la oposición ganara las elecciones parlamentarias del 6 de diciembre de diciembre de 2015 y lo confrontara; las constantes crisis políticas peruanas por sucesivos intentos de juicios parlamentarios de destitución, primero contra el Presidente Pedro Pablo Kuczynski, quien al final dimitió, y luego sobre el actual Presidente Martín Vizcarra, aún en el cargo; la tensión existente en México entre el Presidente Manuel López Obrador y el Congreso mexicano; así como el reciente referendo que el cercano 25 de octubre ha decidido en Chile 
sustituir la autoritaria Constitución impuesta por el tirano Augusto Pinochet. Es un debate inacabado en constante desarrollo que amenaza con prolongarse mucho más en el tiempo.

\section{El debate: presidencialismo vs. parlamentarismo en América latina}

\section{1. ¿Qué se discute en el debate parlamentarismo vs. presidencialismo? ${ }^{3}$}

El debate en América Latina se inició por una fuerte crítica al sistema de gobierno presidencial, al que se le atribuyó ser el causante de la ingobernabilidad ${ }^{4}$ en la región, y que evidentemente se refiere a la ingobernabilidad/gobernabilidad de los sistemas políticos democráticos, ya que hacerlo sobre la de los regímenes no democráticos no tiene ninguna importancia para el constitucionalismo. El asunto que convocaba al debate, el que causaba ansiedad intelectual, era el de la ingobernabilidad democrática, la dificultad de gobernar en un deseado ambiente de paz, de pluralidad social y de libertades políticas, orientado por los valores de equidad y justicia. Ingobernabilidad que se asociaba a una incapacidad de los gobiernos presidenciales para dar respuestas oportunas y adecuadas a las demandas de la población en el contexto del momento -así como en el actual-, debilitándolos, al tiempo que incluso puso en peligro la viabilidad del Estado-nación. Es en este contexto que, desde hace tiempo, en unos momentos con más intensidad que otros, se discute en los predios académicos y políticos de América Latina la implicación del sistema de gobierno presidencial en la inestabilidad de la democracia.

3 En el presente trabajo se toman los análisis de Juan Linz (1988) y de Dieter Nohlen (1992) para exponer los contenidos del debate presidencialismo vs. parlamentarismo en América Latina, que se desarrolló al final de la década de los 80 y durante la de los 90 del siglo pasado, ya que el debate se sigue soportando básicamente en los mismos términos expresados por dichos autores a pesar del transcurso de más de veinte años, y la mayoría de sus argumentos siguen siendo los blandidos en la actualidad. Han cambiado algunos matices y se han añadido algunos giros en las perspectivas con que se aborda la problemática del presidencialismo, como los contenidos en este artículo, pero el sustrato fundamental del debate sigue siendo el mismo.

4 El término gobernabilidad es utilizado por primera vez por Michel Crozier, Sam Huntington y Joji Watanuki (1975) refiriéndose a si la democracia de su tiempo era o no viable como forma de gobierno, esto es, asociada a la crisis de la democracia. Se comenzó a utilizar en América Latina, a mediados de la década de los 80 del siglo pasado, como el necesario direccionamiento y control del liderazgo político-institucional sobre el cambio social para dirigir procesos transformadores de la realidad preservando y fortaleciendo, a la vez, el régimen democrático. En la actualidad también se utiliza para expresar dicho concepto la locución gobernanza, lo que convierte ambos vocablos en una sinonimia, pero algunos autores los utilizan para diferenciar contenidos conceptuales distintos o para diferenciar perspectivas sobre mismo fenómeno político-constitucional. Por ejemplo, Aguilar Villanueva (2016: 34) señala, en vinculación con la crisis de la democracia, que "Gobernabilidad e ingobernabilidad tienen una denotación general, cuando refieren respectivamente a la probabilidad de que las acciones del gobierno tengan como efecto una razonable conducción y ordenamiento de la sociedad en su conjunto o, en sentido contrario, una conducción deficiente y errónea, con el resultado de que se tendrán respectivamente efectos de estabilidad o de conflicto, de prosperidad o de estancamiento, de orden o de descomposición social". Mientras que para este mismo autor autor (54-59) la gobernanza no se refiere a la crisis de la democracia, sino más bien a la acción de gobernar en democracia. "La gobernanza, en el sentido general y básico de proceso de gobernar o acción de gobernar...". Es el "el proceso de gobernar del gobernante legítimo" en "la democracia como forma de gobierno que acredita ser realmente eficaz al tratar los asuntos inquietantes de una sociedad". 
En esa discusión el precursor ha sido Juan J. Linz (1988), quien comenzó argumentando contra el sistema presidencial de gobierno, al que calificó de incorporar principios y supuestos contradictorios que conducen a la inestabilidad de la democracia, y promovió su sustitución con la adopción de sistemas parlamentarios, señalando que "el desempeño histórico superior de las democracias parlamentarias no es accidental". Con lo que cabría suponer que, al adoptarse estructuras orgánico-funcionales presidenciales, el gobierno en América Latina se desvinculó del propósito último de la separación de poderes en los regímenes democráticos, la limitación del poder del gobernante como garantía de la libertad del ciudadano.

Linz postuló que el presidencialismo en sí mismo es inconveniente, porque contiene perversiones congénitas que inevitablemente causan la inestabilidad política y el consecuente debilitamiento de la democracia como régimen. Para Linz el diseño institucional era la causa directa y exclusiva de la ingobernabilidad democrática en la región.

Ante los argumentos críticos de Linz contra el sistema presidencial, Dieter Nohlen (1991) replanteó el debate, interrogándose qué se está discutiendo al evaluar la influencia del presidencialismo sobre la estabilidad, éxito o fracaso de la democracia en América Latina, estableciendo que la diatriba se refería en propiedad a la "relación entre instituciones políticas y rendimiento político". Esto es, se debatía sobre cuál era la incidencia de la variable institucional sobre el resultado político, entendiéndose como su influencia sobre la efectividad de los gobiernos, y la consecuente legitimidad de éstos, que derivaría por último en un mayor o menor apego de las poblaciones a las instituciones democráticas.

Bajo esos parámetros metodológicos de análisis propuestos por Nohlen, Linz estaba sosteniendo que los diseños constitucionales de los sistemas de gobierno, en su crítica al diseño presidencialista, conformaban una variable independiente, entiéndase, una variable que por sí sola causaba el debilitamiento de la democracia. A lo que Nohlen advierte que la cultura de América Latina y las relaciones de poder que subyacen en ella, así como su realidad económica y social, eran tan causantes de las recurrentes crisis de la democracia latinoamericana como la variable institucional. Con esa advertencia, en oposición a Linz, Nohlen consideró que los diseños de los sistemas de gobierno constituían un variable institucional dependiente, vale decir, que para causar un resultado político el presidencialismo tenía que estar asociado a otras variables, fueran éstas relaciones económicas y sociales o fenómenos políticos preinstitucionales. Lo que muestra que en el marco del debate se desarrollaba una confrontación entre el viejo institucionalismo -clásico-, representado por Linz, y uno renovado -el neoinstitucionalismo-, que enarbolaba Nohlen.

Ahora bien, desde la perspectiva del constitucionalismo como pensamiento político, la síntesis del debate entre Linz y Nohlen se puede resumir alrededor los tres problemas siguientes: 1) Si el diseño constitucional de los sistemas presidenciales por sí solo puede ser el causante de la ingobernabilidad democrática. 2) Si producto del diseño constitucional la autoridad presidencial siempre derivará en el ejercicio de un poder excesivo, sin limitación, y consecuentemente arbitrario y autoritario. 3) Si producto del diseño constitucional, que prevé la elección separada del presidente y de los parlamentarios, al quedar integrado el legislativo con una mayoría política distinta y contraria al sector que controla el ejecutivo, siempre conducirá a una fuerte confrontación interpoderes irresoluble.

La anterior problematización permitirá exponer a continuación los argumentos contrapuestos hasta nuestros días sobre el comportamiento del sistema de gobierno presidencial en América Latina. 
Muchos de los estudios sobre los problemas derivados del diseño de los sistemas de gobierno presidenciales en América Latina consisten en lecturas analíticas de los textos constitucionales que concluyen en una supuesta y desmesurada acumulación de "poder" en la rama ejecutiva de los Estados y, dentro de ellas, en los presidentes. Concentración que se supone puede llegar a ser arbitraria por la imprevisión normativa de suficientes y efectivos controles inter e intra poderes sobre la actuación presidencial.

En dichos estudios se suele abordar el presidencialismo desde una perspectiva exclusivamente normativa y abstracta, por lo que es muy común que se confunda la noción de "poder" con la de "potestad o competencia jurídica", se podría decir que trastocan potestas en auctoritas y éste en fuerza, vale decir, que le confieren equivocadamente a las "competencias jurídicas" otorgadas al poder ejecutivo la existencia real de "poder", entendido éste como la capacidad cierta de incidir sin obstáculos sobre el ámbito de lo público y de imponerse sobre los otros actores implicados en los procesos de formación de la política, modificando la realidad en el sentido deseado. Bajo esta lógica normativa y abstracta, se entiende que al contar los presidentes con numerosísimas facultades jurídicas atribuidas por las constituciones y las leyes poseen en consecuencia una gran capacidad de decisión y de ejecución, que por sí les permiten modificar la realidad sin mayores limitaciones. De esta manera, las aproximaciones normativas al estudio del presidencialismo tienden a desdibujar la naturaleza y dimensiones del problema, presentándolo simplemente como una excesiva concentración de poder en manos de los presidentes que, por lo tanto, habría que reducir o limitar ${ }^{5}$.

Sin embargo, la realidad de América Latina mostró por décadas una conclusión contraria, esto es, la paulatina disminución del poder de los presidentes. En efecto, al observar con detenimiento el desempeño de muchos ejecutivos de América Latina, se puede apreciar que sufrieron de una gran debilidad para responder a las exigencias del entorno, siendo incapaces de dar una adecuada y oportuna respuesta a los requerimientos del momento y a las demandas societarias. Ese debilitamiento de la institución presidencial para incidir efectivamente sobre la realidad sitúa el problema en otra dimensión, de naturaleza no constitucional ${ }^{6}$.

Para evaluar la situación del poder efectivo de que dispone el poder ejecutivo para intervenir exitosamente en la realidad, es preciso que se confronte con algunos tipos de recursos de poder, sobre los que pueden actuar distintos componentes de fortalecimiento o debilitamiento de la institución presidencial en América Latina. Estos recursos de poder pueden comprender: 1) El mayor o menor apoyo político al ejecutivo, entendido tanto por el apoyo popular como por el respaldo del poder legislativo. 2) La disponibilidad de recursos presupuestarios por el ejecutivo para hacer efectivo el programa de gobierno. 3) El acceso del ejecutivo a la información y conocimiento de los problemas de interés público y su capacidad de análisis. 4) La disponibilidad efectiva del uso legitimo de la fuerza

5 Es la típica distorsión de algunos análisis jurídicos que llegan a ver el "ser" en el "deber ser". Si bien el análisis jurídico es importante, como se verá adelante, el presidencialismo tiene que ser estudiado desde una perspectiva transdisciplinaria que permita una visión integral y profunda de la complejidad que implica dicho fenómeno político-institucional en América Latina.

6 Un estudio de tipo integral que llega a esta nueva conclusión es el realizado por Álvarez, Fernández Toro y Quintin (1999) sobre el caso venezolano. Dicho trabajo analiza cómo el cambio en los recursos de poder que disponían los distintos gobiernos venezolanos fueron empeorando las condiciones para gobernar y disminuyendo las posibilidades reales de las presidencias para incidir significativamente sobre la realidad. 
a través de los dispositivos policiales y militares, a ser usada como respaldo de la acción del ejecutivo. 5) La ascendencia sobre la opinión pública, que se expresa en la capacidad comunicacional del ejecutivo para convencer a los diversos sectores sociales de la conveniencia de sus políticas y de la necesidad de apoyar sus acciones; y la apariencia que muestra el ejecutivo de poseer poder real.

Mas, sin embargo, un examen comparativo de los recursos de poder de los ejecutivos latinoamericanas durante las últimas dos décadas del siglo $X X$, en cuanto a la disposición o no de dichos recursos de poder, sin duda puede mostrar que la institución presidencial en América Latina era en muchos países muy débil. Con ello, en cuanto al efecto de los sistemas de gobierno presidenciales, se desmentía la conclusión de que la ingobernabilidad era causada por un determinado diseño constitucional que generaba una presidencia extremadamente fuerte y autoritaria. Por el contrario, a pesar de la gran cantidad de competencias jurídicas otorgadas por el ordenamiento jurídico al poder ejecutivo, éste se encontraba imposibilitado de gobernar efectiva y exitosamente.

Mientras que, por el contrario, durante las dos primeras décadas del siglo XXI la capacidad de gobierno de muchos ejecutivos latinoamericanos se incrementó notablemente, adquiriendo un poder efectivo soportado en mayores recursos financieros, un gran respaldo político -popular y parlamentario-, el dominio de los dispositivos para el uso de la fuerza y el apoyo del sistema de justicia, como es evidente que este cambio de las condiciones para gobernar se produjo, entre otros países, en Argentina, Bolivia, Brasil, Ecuador y Venezuela. Aunque esa adquisición de una mayor capacidad de los ejecutivos latinoamericanos para gobernar se logró, en algunos de los casos nacionales, afectando negativamente varios de los supuestos del buen gobierno democrático de la modernidad, tales como, la separación de poderes, en particular la necesaria autonomía del poder judicial, el apego del Estado al derecho, el respeto de las libertades políticas y demás DDHH, así como la pulcritud en el manejo de los recursos del Estado. En verdad, la acumulación de poder efectivo en las presidencias desbarató en varios Estados de la región los diseños constitucionales de separación de poderes y generó al final de las dos últimas décadas otro tipo de problemas. Paradójicamente, varios Estados latinoamericanos comenzaron a adolecer de una alta concentración de poder en la presidencia, pero no por la gran disposición de competencias jurídicas de las que se los acusó en las décadas de los 80 y 90 del siglo pasado, sino por precisamente no respetar las limitaciones que conlleva el ejercicio legítimo de las competencias atribuidas por el ordenamiento constitucional a los órganos y autoridades del Estado, y por la inutilización del sistema de controles que supone la separación de poderes. Ahora sí era cierto que en varios casos nacionales se había perdido el equilibrio entre los poderes con el predominio y supremacía del ejecutivo, derivando en comportamientos presidenciales de tendencia autoritaria, cuando no abiertamente despóticos, que también ha causado a la postre el debilitamiento de la gobernabilidad democrática en sociedades latinoamericanas.

En otro orden de ideas, y no por ello menos importante, además del efecto negativo sobre la gobernabilidad democrática, ya sea por la debilidad de que puede adolecer una presidencia para gobernar, o por el extremo contrario, debido a una concentración de poder efectivo en la presidencia que por falta de medios efectivos de limitación deriva en algún tipo de gobierno de fuerza extraconstitucional, también existen otros factores que inciden negativamente sobre la gobernabilidad democrática, y que deben ser tomados en cuenta como posibles coadyuvantes de las posibles distorsiones institucionales del 
presidencialismo latinoamericano ${ }^{7}$, entre los que se pueden mencionar de manera sintética: 1) El crecimiento del ámbito de lo público, debido a varios motivos, entre los que se pueden mencionar: la aparición de nuevos fenómenos sociales, políticos, ambientales y tecnológicos. 2) La mayor complejidad de los temas públicos debido al señalado desarrollo tecnocientífico, entre otras causas, que requieren un tratamiento técnico además del estrictamente político. 3) El fenómeno de aceleración de la historia, que consiste en que los lapsos durante los que se gestan y concretan los grandes cambios societarios se han venido reduciendo cada vez más. 4) La aparición de nuevas formas de organización social que compiten con el Estado -además de los partidos políticos, sindicatos, grupos empresariales e iglesias, están proliferando entidades internacionales multilaterales de naturaleza pública y organizaciones privadas trasnacionales, así como se multiplican organizaciones de la sociedad que defienden comunidades o intereses difusos-. 5) La cesión de poder de los gobiernos nacionales por la redistribución territorial del poder público: la descentralización -hacia instancias subnacionales-y la integración -hacia instancias supranacionales-.

Los cinco factores antes mencionados obligan a que los ejecutivos actúen en más asuntos, que son más complejos, que deben ser atendidos con mayor rapidez, para lo cual deberán consensuar con una gran cantidad de actores, y que se decidirán y ejecutarán en estructuras públicas descentralizadas sub y supranacionales. Un ejemplo actual de esta complejidad lo es el extraordinario reto que la pandemia del COVID-19 le está ofreciendo a los Estados a nivel mundial, y en especial a los poderes ejecutivos en América Latina.

Ahora bien, regresando a la hipótesis de que la causa de la ingobernabilidad democrática se deba exclusivamente a un inadecuado diseño constitucional de los sistemas de gobierno presidenciales, evidentemente la solución se encontraría en un proceso constituyente, por medio del cual podrían seguirse dos alternativas: 1) Reducirle las competencias jurídicas a los ejecutivos o limitárselas con la imposición de adicionales y mayores controles de los poderes legislativos y judiciales, para que vigilen y redireccionen mejor la actividad de los ejecutivos. 2) Una reforma constitucional más profunda, por la que se sustituyera el sistema de gobierno presidencial por uno parlamentario.

Sin embargo, una reforma constitucional que establezca un sistema de gobierno parlamentario se enfrenta a otro fenómeno generalizado en la actualidad: un cierto desprestigio de los parlamentos, que sufren en muchos de los casos de una carencia de representatividad y la consecuente disminución de su legitimidad, lo que conduciría a la suma de dos posibles poderes debilitados que no necesariamente resolverían el problema de la ingobernabilidad democrática. Por ello el riesgo de adoptar el parlamentarismo en América Latina sería que, lejos de solucionar el problema de gobernabilidad democrática, incluso, podría agravarlo.

\section{Sobre la condición congénita de los sistemas de gobierno}

Otra afirmación que requiere ser analizada es la supuesta superioridad congénita del parlamentarismo sobre el presidencialismo, como lo sostiene Linz,

7 Si bien aquí se establecen algunos factores que están influyendo sobre el rendimiento de los gobiernos, debemos advertir que su impacto negativo puede afectar a cualquier tipo de gobierno, sea de tipo presidencialista o bien parlamentario. Constituyendo factores que generan un desempeño deficiente y un rendimiento desfavorable de los gobiernos en general. 
para garantizar una gobernabilidad democrática suficiente. Aseveración que, en primer lugar, desconoce que los sistemas de gobierno no son presidenciales o parlamentarios puros, y que hay ejemplos en los que existen sistemas de gobierno que son mixtos, o híbridos, o de fases alternas. En propiedad, esta propuesta soportada en la dicotomía que comprende únicamente dos paradigmas: el parlamentarismo y el presidencialismo, está partiendo de una tipología reduccionista de los diseños de sistema de gobierno existentes. En efecto, salvo el antiguo parlamentarismo inglés y el tradicional presidencialismo estadounidense, todos los demás países cuentan con diseños de sistemas de gobierno que se diferencian de una u otra manera a esos dos casos paradigmáticos. No sólo porque se pueden encontrar en un punto más o menos intermedio entre ambos, sino porque, además, suelen contar con instituciones que en nada se parecen a los mencionados "modelos".

En cualquier caso, el señalar que cada uno de estos modelos de sistema de gobierno tiene ventajas o perjuicios para la gobernabilidad que le son congénitos es una tesis osada no comprobada en los estudios comparados. Mientras Linz indica que el parlamentarismo es mejor que el presidencialismo porque resuelve las crisis políticas, Nohlen acierta al señalar que no se puede comparar el presidencialismo latinoamericano con el parlamentarismo europeo sin cometer un error metodológico. Vale decir, se debería comparar el presidencialismo latinoamericano con el parlamentarismo latinoamericano, así como el parlamentarismo europeo con el presidencialismo europeo. Comparar cada uno de los dos modelos constitucionales de sistemas de gobierno en el mismo contexto y no en entornos distintos o en abstracto. En definitiva, que tanta importancia como la puede poseer el diseño normativo del sistema de gobierno presidencial, la tiene también la propia región latinoamericana con su historia y su cultura como variables que inciden sobre la gobernabilidad de las democracias. Además de mencionar las tradicionales relaciones de poder y de distribución de la riqueza como otros factores a ser tomados en cuenta. Por último, recuérdese lo señalado en el apartado anterior, en cuanto a que la ausencia de recursos de poder para gobernar igualmente afectaría al ejecutivo en un sistema de gobierno parlamentario.

\section{Un abordaje integral del presidencialismo en América Latina}

En otro orden de ideas, tanto los análisis que ubican las causas de la ingobernabilidad democrática exclusivamente en los diseños constitucionales de los sistemas de gobierno presidenciales, como los que, por el contrario, las encuentran solo en la carencia de recursos de poder de los ejecutivos, no alcanzan a comprender la complejidad de las condiciones que la originan, conduciendo a equívocos en las propuestas para su solución. Por ello es preciso definir el fenómeno del presidencialismo, el cual puede denotar dos perspectivas distintas, pero vinculadas entre sí, ambas de importancia para el constitucionalismo:

- Una, la más común, se corresponde a un diseño de sistema de gobierno con una particular distribución de funciones y su correspondiente separación

8 En América Latina están como ejemplos los casos de Argentina, Perú y Venezuela, en los que sistemas presidenciales contienen instituciones típicas de los sistemas parlamentarios, por lo que se podrían tipificar como sistemas mixtos o híbridos. Más en el caso de Venezuela, que su sistema de gobierno podría comportarse en determinadas coyunturas políticas como un sistema de gobierno muy parecido al de Francia de la cohabitación (Fernández Toro, 2001). 
orgánica -la ingeniería constitucional-. Es la perspectiva tradicional.

- La otra, implica más bien una cultura en la relación entre el Estado y la sociedad, comprendiendo un modo de ejercer el gobierno por quienes lo detentan y una expectativa de la población sobre la actuación del mismo. Es una cultura que soporta a una determinada relación de poder entre la institucionalidad del Estado expresada por el sistema presidencialista y los actores del entorno. Esta forma de ejercicio del poder del Estado convierte al presidente en una figura clave del sistema político y en actor fundamental para la gobernabilidad. Así el presidencialismo surge como una dimensión cultural que condiciona el comportamiento de los ciudadanos, de las élites y de la propia burocracia del Estado en el proceso político.

Ambas facetas del presidencialismo se encuentran entrelazadas, y estas dimensiones del fenómeno se retroalimentan mutuamente.

Ahora bien, como relación de poder entre los gobiernos -en stricto sensu: legislativo y ejecutivo- y los gobernados, hace referencia a los mecanismos de intermediación y representación de los sistemas políticos, el presidencialismo es una de las instrumentaciones de legitimación y eficacia del proceso de formación de la política. Vale decir, que hay una estrecha relación entre el comportamiento efectivo de los sistemas de gobierno presidenciales y los mecanismos y modos concretos que se adoptan para ejercer la forma de gobierno democrática. Por ello es que André Hariú (1980) al comentar el presidencialismo latinoamericano llegó a denominarlo como "presidencialismo autoritario teñido de populismo". Resultando que el diseño constitucional de los sistemas de gobierno, su funcionamiento fáctico y la viabilidad de los sistemas políticos latinoamericanos democráticos son inseparables e inciden entre sí.

Se debe recordar, nuevamente, que el óptimo funcionamiento de los sistemas de gobierno y su relación con la gobernabilidad democrática depende también del buen gobierno, como lo expresa Nohlen (1991) al indicar que "la consolidación democrática y su éxito, excede los límites de la institucionalidad y tiene que ver con la eficiencia del gobierno".

En definitiva, bajo un enfoque transdisciplinario se puede obtener una visión más integral del fenómeno en estudio, se puede comprender que los diseños constitucionales de los sistemas de gobierno presidenciales, son efectivamente una variable dependiente, que debe seguir estudiando y que puede aportar soluciones en conjugación con otros factores que también influyen en la ingobernabilidad de la democracia en la región.

Como efecto de los cambios en los recursos de poder de las presidencias y de los nuevos factores que deben enfrentar los gobiernos en la actualidad, los sistemas de gobierno presidenciales de América Latina se encuentran sufriendo problemas que se pueden reunir en tres grupos de naturaleza distinta, a saber:

\section{Problemas cuyo origen es el diseño institucional del sistema de gobierno presidencial}

Desde una perspectiva exclusivamente normativa -análisis de lo previsto constitucionalmente sobre la estructura orgánico funcional del sistema de gobierno presidencial-, se exponen los tres principales problemas que puede considerarse que derivan de los diseños constitucionales en América Latina:

a) La mayoría de los sistemas de gobierno presidenciales no promueven en todos los escenarios políticos la colaboración entre los poderes legislativo y ejecutivo. 
Una crítica general al presidencialismo, la más sólida, se refiere a la legitimación democrática que por separado obtiene tanto el poder legislativo como el poder ejecutivo, dado que los integrantes de ambos poderes son electos de manera directa por el pueblo. Con ello un resultado electoral bastante común es que el presidente resulte de un sector político y el parlamento lo sea de otro, lo que puede conllevar a una situación de permanente enfrentamiento o, a lo menos, de indiferencia política con ausencia de colaboración. En todo caso, la crítica en América Latina es que los diseños del sistema de gobierno presidencial no han servido para promover, en distintas coyunturas políticas, la colaboración entre los poderes mediante la negociación entre el ejecutivo y la oposición, para que las acciones gubernamentales fueran compartidas. Esto no significa que no existieran casos de colaboracionismo de la oposición con el ejecutivo, pero dicha colaboración por acuerdos o compromisos no se derivaron del diseño institucional sino de la simple y pura voluntad política de las partes por conveniencia mutua, esto es, de una cultura democrática con "visión de Estado". La crítica lo que trata de resaltar es la necesidad de que los diseños institucionales de un sistema de gobierno siempre debería promover la negociación política entre el ejecutivo y la oposición, y evitar el obstruccionismo parlamentario o los ejecutivos aislados institucionalmente. El detalle es que los incentivos para la colaboración ejecutivo-oposición suelen ser de carácter estrictamente político, difícilmente previsibles constitucionalmente.

b) Las crisis de gobierno derivadas de los conflictos entre los poderes legislativo y ejecutivo no tienen salidas institucionales democráticas.

La segunda crítica se refiere a que las constituciones no prevén mecanismos institucionales para resolver por la vía democrática las crisis de gobierno cuando los poderes ejecutivo y legislativo se enfrentaban definitivamente y se neutralizaban o dañaban mutuamente hasta provocar la parálisis institucional del Estado, incluso socavando la estabilidad de todo el sistema político. Y en efecto, se puede advertir que los períodos constitucionales rígidos de los poderes, de cuatro, cinco o seis años, y la inexistencia de mecanismos para el adelanto de las elecciones hace que el enfrentamiento político y el mutuo obstruccionismo institucional alarguen por años las crisis político-institucionales o, en otros términos, empantanen las relaciones entre los poderes y, en particular, entre el ejecutivo y la oposición. Muchas de las veces el impeachment o los juicios de destitución del presidente han agravado las crisis. La solución propuesta es la adopción de los referendos populares revocatorios del mandato presidencial y la convocatoria anticipada de elecciones parlamentarias, pero en el caso venezolano que se ha puesto en práctica el referendo revocatorio después de la mitad del período presidencial, este mecanismo democrático ha sido impedido desde el ejecutivo inhabilitando esta salida institucional, pacífica y democrática.

c) La concentración de las funciones de la jefatura de Estado y de la jefatura de gobierno -ejecutivo nacional- puede hacer ineficiente e ineficaz la acción gubernamental.

Se critica que la concentración de las jefaturas del Estado y del gobierno en una sola autoridad: el presidente, originan múltiples consecuencias negativas. Una primera es, la confusión entre las denominadas políticas de Estado y políticas de gobierno. La unidad de las jefaturas en una única autoridad 
lleva a confundir los roles que se derivan de cada una, conduciendo a que las políticas de Estado, correspondientes a los desiderátums fundamentales y de largo aliento de la nación cedan en favor de coyunturales políticas gubernamentales que son de impacto político inmediato y responden a intereses concretos.

Otra consecuencia es que los presidentes no pueden atender al mismo tiempo, con eficiencia y eficacia, las obligaciones que se derivan de ambas jefaturas. Más cuando la concentración de las jefaturas en los presidentes fuerza a que en ellos recaiga un sin número de actividades en ámbitos de materia muy disímil, y de complejidad, importancia y urgencia desigual, a pesar de que en el ejercicio que se deriva de cada una de las jefaturas el llamado fenómeno de aceleración de la historia exige tomar más decisiones en menos tiempo y bajo condiciones en las que se dispone de escasa información.

En tercer lugar, se puede decir que la confusión de las jefaturas del Estado y del gobierno -ejecutivo nacional- ha podido desnaturalizar el principio de división del poder como una garantía a la libertad y como racionalidad organizativa de la especialización de las funciones del Estado. En efecto, muchos autores han sostenido que los diseños constitucionales en América Latina obligaban una acumulación de poder institucional en el presidente que conduce el comportamiento institucional de esta figura hacia la prepotencia institucional, la irresponsabilidad política del titular del cargo y, en definitiva, que impide se ejerza un control efectivo por parte de los otros poderes, desvirtuando el sentido de las distribuciones funcional -horizontal-y territorial-vertical- del poder público y el complejo sistema de controles y equilibrios que se establecieron precisamente para evitar dicha concentración.

\section{Problemas cuyo origen se encuentra ubicado en la cultura social y en la praxis política}

Ahora bien, hay problemas que no tienen su origen en el diseño constitucional de los sistemas de gobierno presidencial, y su causa es más bien una variable de naturaleza subjetiva, individual o colectiva, como lo son: la conducta del titular de la presidencia, que determina finalmente la apreciación que se tiene colectivamente sobre el ejercicio del gobierno; $y$, la cultura social y la praxis de los actores políticos que hace en sus relaciones con la presidencia una referencia de poder, a la que los sectores y agentes políticos o sociales le confieren importancia y con la que desean relacionarse para obtener determinados beneficios. Esos problemas serían:

a) El sistema político puede ver afectada su legitimidad por el desempeño inadecuado de una sola autoridad: el presidente.

La confusión presidente-Estado y su impacto sobre el régimen democrático. Si el sistema presidencial puro, o cualquier modalidad atenuada, sea por su diseño normativo o por la praxis política, propende a que el presidente desarrolle un exacerbado protagonismo político-institucional, y si a ello se le agrega que las sociedades latinoamericanas se rigen más por las relaciones personales que por las institucionales -subjetivación de la política-, se tendrá una cultura y dinámicas políticas e institucionales orientadas bajo el signo del personalismo. De allí que el resultado político de la acción de gobierno dependan en exceso de la actitud y aptitud de la persona titular 
de la presidencia, de su hiperliderazgo. Además, como se señalará adelante, si al individualismo en la dinámica de trabajo de un ejecutivo, en sus formas y en sus contenidos, se le agrega un posible comportamiento caudillesco en su relación con la población, se obtendrá un cuadro en donde la personalidad y el desempeño individual del presidente, su hiperliderázgo, será una variable con mucho peso en el resultado del sistema político en su conjunto.

Dado que la vinculación de los presidentes con las políticas de los ejecutivos es muy estrecha y personal, al punto de que cualquier fracaso se percibe como una derrota del presidente, la estabilidad del sistema político puede en algunas coyunturas soportarse en demasía sobre el desempeño y la imagen del presidente. En consecuencia, cuando la gestión del presidente como jefe del ejecutivo nacional es valorada negativamente por la población, no sólo se desgasta y deteriora su figura como jefe de gobierno, sino que, por su indisoluble carácter unipersonal, también es afectada la jefatura del Estado, esto es, queda impactada negativamente la imagen de la máxima representación institucional del Estado democrático, deteriorando a su vez la propia percepción popular sobre el Estado. En otros términos, el mal desempeño del presidente como jefe del ejecutivo nacional puede llegar a deslegitimar al mismo tiempo a la autoridad máxima de todo el Estado, hasta desacreditarse no sólo una gestión de gobierno sino toda la acción del Estado.

Es evidente la necesidad de promover la objetivización de las políticas sectoriales despersonalizándolas de la figura presidencial, y para ello es necesario que la acción de los ejecutivos sea producto de una labor política más colectiva, a cargo de los gabinetes o consejos de ministros, otorgándole más protagonismo a estos órganos colegiados y a los ministros por separado. De otro lado, el rol del partido del presidente o de los partidos de una alianza presidencial, además de su función contralora de la gestión presidencial, debe ser también protagonista como un colectivo del que surgen las propuestas de políticas sectoriales.

b) El desarrollo del caudillismo presidencial puede hacer autoritaria la acción de gobierno.

Desde una perspectiva cultural de las relaciones de poder, el caudillismo, como una un valor social y práctica política del ejercicio del poder, nace en América Latina durante el período histórico de la independencia, cuando el régimen colonial español es demolido y en su reemplazo la institucionalidad estatal da paso inicialmente a relaciones de poder no institucionalizadas, o estructuradas jerárquicamente bajo el poder militar de los ejércitos libertadores. El resultado fue el establecimiento de sociedades bajo una cultura autoritaria, a pesar que el proceso independentista y republicano de América Latina era alentado, entre otros factores, por ideales libertarios y democráticos. La permanencia de esta estructura de poder caudillesco condujo en muchos casos a que los diseños constitucionales de los sistemas de gobierno, que formalmente concentraron en el presidente una enorme cantidad de potestades jurídicas, potenciara el comportamiento autoritario de quien alcanza la presidencia, convirtiéndose en la persona con mayor poder en todo el Estado y la sociedad, al grado de que el ejercicio del cargo llegue a ser absolutamente arbitrario.

A pesar las garantías constitucionales a la autonomía de los poderes y de la previsión de medios de control sobre la presidencia, lo cierto es que ha sido difícil contener el poder político y social real desarrollado por los presidentes 
en América Latina, y se ha frenado sólo cuando éste ha perdido de manera fáctica el liderazgo político social, esto es, cuando ha dejado de ser caudillo porque se debilitó en el proceso político, o porque el presidente se autolimitó al asumir un ejercicio moderado del poder. En todo caso y como se expuso arriba, el poder real del presidente no depende exclusivamente de las atribuciones jurídicas que la constitución y las leyes le hayan otorgado, sino más bien de los recursos de poder que maneje en el ejercicio del gobierno.

c) El protagonismo presidencial exacerbado puede distorsionar cualquier sistema de responsabilización del desempeño.

Hoy se reconoce universalmente la obligación de toda autoridad pública de rendir cuentas de su gestión para ser evaluada y controlada, lo ha sido denominado en castellano como responsabilización -en adaptación de la locución inglesa accountability-. Así, la eficiencia, eficacia y efectividad de la acción del Estado debe ser evaluada política, social y técnicamente, para lo cual es necesario examinar la administración de recursos, la calidad de los productos y el impacto de los resultados institucionales, tanto por el desempeño institucional de los organismos estatales como por la gestión individual de sus autoridades y funcionarios. Esta evaluación tiene un componente técnico y otro político, dado que la evaluación no supone exclusivamente una validación institucional sino que también hay que determinar la opinión de la población en tanto que usuaria o beneficiaria de los servicios y bienes generados por la acción de gobierno. En cuanto a su propósito político, la evaluación de la gestión de los diversos componentes orgánicos del Estado supone afianzar medios democráticos que permitan hacer efectiva la llamada responsabilización de las autoridades por parte de los ciudadanos. Ahora bien, la actuación del presidente puede ser tan invasiva, tan omnipresente en todos los ámbitos públicos estatales que crea una percepción errónea en la gente de que él es, formal y realmente, la autoridad encargada de actuar, de alcanzar las metas de satisfacción social en todas las áreas, y con ello desvía la atención pública sobre las otras autoridades, funcionarios y unidades orgánicas del Estado que deben informar y dar cuenta de su gestión y ser evaluadas políticamente. En estas circunstancias, al ciudadano no le queda claro si un determinado problema que lo afecta, en el funcionamiento de un servicio o en la construcción de una obra corresponde a un gobernador, a un alcalde, a un ministro, o a un órgano legislativo o cualquier otra autoridad u organismo distinto al presidente.

El ilimitado protagonismo del presidente ocurre incluso en desmedro de una evaluación justa sobre su propia eficiencia, eficacia y efectividad, ya que es visto como la autoridad competente para todo y, en consecuencia, se lo encuentra responsable de todo. Así, la sobreestimación popular del alcance real del poder del presidente, debido a su tendencia a intervenir en todo, termina por revertirse en su contra. Por este motivo al presidente se le exige más de lo que realmente puede dar, y se distorsionan todos los sistemas de evaluación del desempeño institucional e individual en la gestión pública. Todo ello contrario a la regla básica que se debe seguir para el diseño de las estrategias dirigidas a incrementar la efectividad de la acción presidencial: eludir la tentación de que la presidencia sea envuelta en todos los asuntos públicos (Holbrooke, 1992), y también contraria a la recomendación de proteger a la presidencia de las presiones sociales, facilitando su concentración en una pequeña lista de esfuerzos principales (Kelman, 1992). 
La política en la cultura latinoamericana -con algunas excepciones nacionales- hace difícil que el rol institucional de los poderes y órganos del Estado, que ha sido previsto por los diseños constitucionales, se autonomice y se desarrolle por encima de los intereses particulares, sean estos individuales, de sectores sociales o partidistas. Por ello, en cuanto al control parlamentario sobre la presidencia, cuando la mayoría presidencial coincide con la mayoría del parlamento -sobre todo si es una mayoría unipartidista aplastante-, la separación entre poderes desaparece y el partido del ejecutivo sustituye al Estado (García-Pelayo, 1985: 57 y ss.), y garantiza la impunidad del presidente. De otra parte, en sistemas políticos con regímenes representativos en los que no hay controles populares directos sobre sus representantes que permitan establecer la responsabilidad política del presidente ante el pueblo -como por ejemplo lo suelen ser los plebiscitos y referendos revocatorios y consultivos ${ }^{9}$-, también se impone la impunidad presidencial.

Un medio de responsabilización del presidente es la posibilidad de que éste sea candidato a ser electo para un nuevo período. De ser electo nuevamente se lo estaría evaluando positivamente, mientras que si pierde la elección sería una sanción política contra su gestión. Este es un sistema de incentivos para un mejor esfuerzo presidencial, aunque posee dos posibles debilidades, la primera es que el presidente en ejercicio tienda a ser populista para ser nuevamente electo, lo que afectaría la idoneidad y calidad de las políticas sectoriales. La segunda es que la posibilidad de reelección presidencial, sin que se haya limitado el número de mandatos que un presidente podría ejercer de manera consecutiva, puede desarrollar pretensiones de continuismo personal que alienten ignorar la voluntad popular mediante el fraude democrático, como ha ocurrido en los casos de Venezuela y Bolivia.

\section{Problemas cuyo origen se encuentra en la capacidad de gobierno}

Al lado, y soportados en los problemas de diseño y de cultura y práctica política, aparecen los problemas de la conducción del ejecutivo cuya labor corresponde a la presidencia. Estos problemas son tanto los referidos a la actitud y aptitud gerencial del presidente y de su gabinete de ministros, como los de recursos y apoyo técnicos (Álvarez, Fernández Toro y Quintín, 1999). En general se puede encontrar en América Latina una disfuncionalidad de los llamados ministerios

9 Como excepción, el Artículo 72 de la Constitución de la República Bolivariana de Venezuela (Gaceta Oficial N 5.453 Extraordinario del 24 de marzo de 2000) establece:“Todos los cargos y magistraturas de elección popular son revocables.

Transcurrida la mitad del período para el cual fue elegido el funcionario o funcionaria, un número no menor del veinte por ciento de los electores o electoras inscritos en la correspondiente circunscripción podrá solicitar la convocatoria de un referendo para revocar su mandato.

Cuando igual o mayor número de electores o electoras que eligieron al funcionario o funcionaria hubieren votado a favor de la revocación, siempre que haya concurrido al referendo un número de electores o electoras igual o superior al veinticinco por ciento de los electores o electoras inscritos o inscritas, se considerará revocado su mandato y se procederá de inmediato a cubrir la falta absoluta conforme a lo dispuesto en esta Constitución y en la ley. La revocación del mandato para los cuerpos colegiados se realizará de acuerdo con lo que establezca la ley.

Durante el período para el cual fue elegido el funcionario o funcionaria no podrá hacerse más de una solicitud de revocación de su mandato". 
de la secretaría de la presidencia o de cualquier oficina presidencial que con otro título se supone debería darle apoyo estratégico y logístico inmediato y exclusivo a la labor presidencial, en muchos casos debido a la desviación de su misión y carencia de recursos. De todas maneras, las fallas que se han detectado en toda América Latina (Dror, 1989; Matus, 1990), son las siguientes: 1) Sobrecarga cuantitativa de trabajo, que incluye muchas actividades rutinarias y rituales que ocupan gran parte del tiempo y energía del Presidente; sus agendas están siempre saturadas e invierten parte significativa de su tiempo en mantener su posición de liderazgo. 2) Sobrecarga cualitativa de trabajo, derivada de complejos problemas no bien estructurados y sin soporte adecuado de conocimientos, a lo cual contribuye la existencia de sistemas altamente centralizados de gobierno. 3) Sometimiento a fuertes tensiones situacionales, que crean peligrosas posibilidades de error en el manejo de decisiones en situaciones de crisis. 4) Limitaciones a la vida normal, como consecuencia de la protección cortesana que ejerce su entorno, que a su vez es una respuesta a las presiones por acceder al presidente. Dicha protección, si bien aparece como un control de puertas, termina por operar como un control de su mente, por lo que el presidente pierde parte de su capacidad de vivencia y percepción directa de la realidad. 5) Tendencia al mal uso del tiempo y la atención, en la medida en que el presidente siente que la formalidad de la planificación de su agenda lo aprisiona y reduce su tiempo de libertad. 6) Refuerzo de los defectos y errores, como consecuencia del comportamiento adulador de su círculo más estrecho y la protección frente a las críticas. 7) Manipulación hacia opciones restringidas, es decir, el presidente se ve limitado al conocimiento de muy pocas opciones. 8) Hipertrofia de su seguridad y confianza en su experiencia, que le lleva a reforzar su pragmatismo y a desvalorizar la asesoría calificada. 9) Limitada capacidad para discernir con profundidad las cualidades y deficiencias de los equipos técnicos en los cuales debe confiar; hay una propensión a privilegiar la lealtad por sobre la capacidad; la relación del presidente con los técnicos tiende a ser una relación de fe y credibilidad, en vez de ser una interacción sinérgica de experiencias y conocimientos entre la política y la técnica. 10) El peso de la responsabilidad y la amortiguación de la información produce el miedo a innovar, reforzando la tendencia a buscar refugio en la corriente de opinión dominante. 11) Dificultad para trabajar en equipo; al presidente suele resultarle incómodo trabajar en equipos de personalidades, con intereses y formación muy diversa. En los países de la región se respeta, en general, la formalidad de las sesiones de gabinete -a diferencia de los Estados Unidos-, pero los problemas realmente importantes se tratan en pequeños grupos, más homogéneos, fuera de los consejos de ministros o consejos de gobierno.

\section{Adecuación de los sistemas de gobierno presidenciales para garantizar la gobernabilidad democrática en América Latina}

En un ejercicio propositivo desde la perspectiva constitucionalista, se pueden formular algunas orientaciones generales sobre las transformaciones de los diseños que requieren los sistemas de gobierno presidenciales en América Latina para contribuir con la consolidación de la gobernabilidad democrática, que deben comprenderse como recomendaciones genéricas que deben contrastarse con cada realidad nacional, y que de ninguna manera es una receta de medidas aplicable universalmente.

En primer lugar, uno de los grandes lineamientos de las reformas político-institucionales que se pueden sugerir, es incorporar en los respectivos 
ordenamientos constitucionales nacionales la sustitución del actual paradigma de ejercicio del gobierno por uno nuevo que se puede disgregar en dos aspectos diferenciados, pero estrechamente integrados: 1) la necesidad de un nuevo diseño de los sistemas de gobierno -lo normativo- y, 2) un cambio en el modo de ejercer las funciones del Estado -lo cultural-. En ambos elementos se deberían seguir las pautas siguientes:

\section{De naturaleza política}

Tanto en los rediseños constitucionales como en los cambios culturales se tiene que perseguir la democratización de lo público a la vez que un mejor rendimiento político de las instituciones estatales, superando las distorsiones elitista y populista de la democracia.

a) Una mayor y mejor participación de los ciudadanos en la designación de las máximas autoridades que los han de representar en el ejercicio de las funciones del Estado, como manera de fortalecer la legitimidad de origen del mandato presidencial, así como de los vicepresidentes y de figuras similares a los primeros ministros parlamentarios que conformen el alto gobierno, de los parlamentarios y, de ser posible, de las autoridades de los otros poderes. Ello implica, de una parte, revisar los sistemas electorales por los que se eligen popularmente a las máximas autoridades del Estado, en particular los que ejercen las jefaturas de Estado y de gobierno y quienes integran el parlamento. Lo que supone evaluar en cada caso nacional la pertinencia de la exigencia de obtener determinadas mayorías porcentuales de votos para alcanzar los cargos, la doble vuelta electoral, la personalización del voto y la necesidad de la proporcionalidad de la representación parlamentaria. Y, de otra parte, se podrían incluir en los diseños constitucionales instancias y mecanismos de participación de la sociedad organizada en la selección y designación de las autoridades de los otros poderes y órganos del Estado de rango constitucional que no siendo de elección popular tengan que ser designados por los parlamentos, como por ejemplo, los magistrados de las cortes o tribunales supremos de justicia y constitucionales, los fiscales y contralores generales, los defensores del pueblo y los máximos directivos de los órganos electorales. Con ello se persigue una mayor transparencia en los procesos de selección, un consenso más amplio en las designaciones y una mayor legitimidad de origen de las autoridades estatales que no sean electas popularmente mediante el voto directo de los ciudadanos.

b) Se pueden mejorar los medios de relacionamiento entre los poderes legislativo y ejecutivo, en el sentido de garantizar una comunicación fluida y permanente entre el sector político que ejerce el ejecutivo y la oposición, una colaboración mínima en función de los intereses nacionales y el logro de consensos políticos suficientes para lograr los fines generales del Estado en beneficio de toda la sociedad. En definitiva, para ampliar los consensos políticos, minimizar los conflictos entre poderes y evitar las crisis de gobierno. Para ello se requiere coadyuvar a la conformación de mayorías políticas sólidas para ejercer las funciones ejecutiva y legislativa del Estado. A la vez, es necesario que se puedan conformar mayorías estables en el parlamento y que se simplifique el número de fracciones parlamentarias, para mejorar las funciones de aglutinación de intereses difusos, de intermediación y de representación política y para simplificar el proceso de debate, negociación y construcción de consensos políticos. 
c) Establecer mecanismos de participación y control sociales sobre en la actividad del ejecutivo. Con ello se pretende, en primer lugar, incorporar procesos de cogobierno entre las autoridades ejecutivas y los ciudadanos para la gestión de lo público. Esto es, medios de participación directa o semidirecta de la población en decisiones y acciones del ejecutivo. Y, en segundo lugar, procesos de control social sobre la gestión de lo público, de manera que se haga efectiva la responsabilización de las máximas autoridades estatales. Ello implica mejorar los mecanismos de representación -participación indirecta de la población- con la inclusión de otros de participación directa y semidirecta de la población en la formación de la política. Con todo ello se persigue la ampliación de los consensos sociales y mejora de la legitimación de desempeño de las autoridades.

d) Además de prevenir los conflictos políticos, también es preciso solucionar las crisis de gobierno que aparezcan. Ahora bien, algunos conflictos entre los poderes ejecutivo y legislativo que pueden generar crisis de gobierno no trascienden de ser una medición institucional entre las fuerzas del ejecutivo y las de la oposición, que pueden ser resueltos simplemente mediante la aplicación de mecanismos formales de orden constitucional. Pero otros conflictos pueden reflejar una confrontación política más profunda en el seno de la sociedad. Este último tipo de conflictos políticos no se resuelven con la simple utilización de los resortes formales y es preciso convocar institucionalmente la participación de toda la sociedad para obtener una solución final. Por ello no sólo se debe institucionalizar el tratamiento formal de las relaciones de conflicto entre las distintas fuerzas del ejecutivo y de la oposición, mediante mecanismos de control y de equilibrio entre los poderes legislativo y ejecutivo, sino que además es necesario prever los casos en los que la magnitud de la crisis política requiere convocar a procesos electoral para lograr su solución definitiva, que podría resultar en una redefinición de las mayorías y minorías políticas con el consecuente reacomodo de las distintas fuerzas políticas en los poderes ejecutivo y legislativo.

\section{De flexibilización organizacional para la adaptación a los cambios}

Con una organización adaptativa del ejecutivo se podría, de una parte, mejorar la gestión presidencial en los casos en que la mayoría parlamentaria -monopartidista o por alianza entre partidos- coincida políticamente con el presidente $y$, por lo tanto, éste posea todo el apoyo del parlamento. En esta situación, si bien el presidente acumula las jefaturas de Estado y de gobierno, empero, puede mejorar el ejercicio de la jefatura de gobierno con el apoyo de una figura parecida al Presidente del Consejo de Ministros peruano, el Jefe de Gabinete argentino o el Vicepresidente Ejecutivo venezolano. A la vez que se podría solucionar la confusión entre políticas de Estado y políticas gubernamentales con dicho rediseño orgánico-funcional de las jefaturas de Estado y de gobierno, y una consecuente modificación de las relaciones entre los poderes ejecutivo y legislativo.

De otra parte, en los casos en que la mayoría parlamentaria sea contraria al presidente, y éste no cuente con el apoyo parlamentario necesario para ejercer óptimamente sus competencias, la jefatura de gobierno podría ser cedida a un líder de la mayoría parlamentaria mediante un cargo como los antes indicados. En este segundo caso, se pretende mejorar estabilidad y éxito gubernamental mediante una relación de colaboración entre los poderes legislativo y ejecutivo a través de acuerdos políticos el ejecutivo-legislativo. Se trata de que el comportamiento de 
los sistemas de gobierno tienda a ser más flexible, adaptándose a los cambios en las circunstancias políticas, de manera que en unas coyunturas se comporten como sistemas propiamente presidencialistas y, en otras, operen como lo suelen hacer los sistemas de gobierno parlamentarios o los mixtos llamados por algunos autores semipresidenciales o de fases alternas, dependiendo siempre del resultado de la integración política de la presidencia y del parlamento y por lo tanto de las correlaciones entre las fuerzas políticas correspondientes.

\section{Bibliografía}

Aguilar Villanueva, L. F. (2016). Democracia, Gobernabilidad y Gobernanza. México: INE. Alvarez, A., Fernández Toro, J. C., \& Quintín, A. (1999). Los Desafíos de la Institución Presidencial en Venezuela. Gobernabilidad Democrática y reforma Constitucional del Sistema de gobierno. Caracas: CLAD/Instituto de Estudios Políticcos de la UCV.

Arroyo, I. (2002). La República Imaginada. En J. A. Aguilar y R. Rojas (coords.). EI Republicanismo en Hispanoamérica. Ensayos de Historia Intelectual (pp. 47-62). México: CIDE/FCE.

Crozier, M., Huntington, S., \& Watanuki, J. (1975). The Crisis of Democracy: Report on the Governability. New York: New York University Press.

Dror, Y. (1989). Enfrentando el futuro. México: Fondo de Cultura Económica.

Fernández Toro, J. C. (2004). El Nuevo Paradigma de Ejercicio del Gobierno. El sistema de gobierno en la Constitución de 1999. En R. Viciano Pastor y L. Salamanca (coords.). El Sistema Político en la Constitución Bolivariana de Venezuela (pp. 611-696). Caracas-Valencia: CEPS-Instituto de Estudios Políticos/UCV-Vadell Hermanos.

García-Pelayo, M. (1985). Las Transformaciones del Estado Contemporáneo. Madrid: Alianza Universidad.

Grau, L. (2011). El constitucionalismo americano: materiales para un curso de historia de las constituciones. Madrid: Dykinson.

Hauriou, A., Gicquel, J., \& Gélard, P. (1980). Derecho Constitucional e Instituciones Políticas. Barcelona: Ariel.

Holbrook, R. (1992). Memorandum to the President-Elect. Sujet Harnessing Prodess to Purpose. Carnagie Endowment and Institute for International. Economics Commission on Government Renewal.

Kelman, S. (1992). La política pública en el Estado Moderno. Buenos Aires: Grupo Editor Latinoamericano.

Linz, J. J. (1988). Democracia presidencialista o parlamentaria ¿Hay alguna diferencia? En Consejo para la Consolidación de la Democracia. Presidencialismo vs. Parlamentarismo: materiales para el estudio de la Reforma Constitucional (pp. 19-43). Buenos Aires: EUDEBA.

Matus, C. (1990). El líder sin Estado Mayor. Caracas: ILDIS.

Montesquieu, C.-L. S. (1748/2003). El Espíritu de las Leyes. Barcelona: Origen. 